\title{
Understanding Technical Aspects of Cloud Computing with different Computing Models and its Benefits
}

\author{
Saiyed Faiayaz Waris \\ Department of Computer Science \\ School of Computing and Informatics \\ Mizan Tepi University, Ethiopia
}

\author{
Mohammed Khalid Kaleem \\ Department of Computer Science \\ School of Computing and Informatics \\ Mizan Tepi University, Ethiopia
}

\begin{abstract}
Cloud computing is the development of parallel computing, distributed computing, grid computing and virtualization technologies which defines the shape of a new era. Cloud computing is an emerging model of business computing. It means storing and accessing data over the internet instead of your computer's hard drive. That means all the data what you are going to access is on air i.e., on internet. In this paper we have enlighten different computing models from which we have finally concluded that Cloud Computing is one of its types which is a combination of cluster and grid computing models. Many people have different opinion about the term Cloud Computing, many even says that it is a new technology and new establishment on internet, but Cloud Computing is available on internet since the day the Internet was evolved. In this paper we have focused on technical aspects of cloud computing and have explained it via different computing models. This paper provides a better understanding of the cloud computing and also explains the evolution of it by understanding the emergence of internet with benefits.
\end{abstract}

\section{Keywords}

Cloud Computing, Computing Models, Services in Cloud Computing, Evolution of Cloud Computing, Characteristics and Benefits of Cloud Computing.

\section{INTRODUCTION}

In simple terms Cloud Computing means storing and accessing data and programs over the Internet instead of your computer's hard drive [1]. Different people have different opinion about Cloud Computing; hence let us discuss only the technical part of Cloud Computing referred as Computing Model. Cloud computing is a general term for the delivery of hosted services over the internet. Cloud computing traces its origins back to the 1960 s, when the computer industry recognized the potential benefits of delivering computing as a service or a utility.

Gajender Pal et al., (September 2014) describes as Cloud computing is a way of leveraging the Internet to consume software or other IT services on demand. Users share processing power, storage space, bandwidth, memory, and software. With cloud computing, the resources are shared and so are the costs. Users can pay as they go and only use what they need at any given time, keeping cost to the user down. Cloud computing is very much a business model as well. Providers of cloud computing solutions, whether they are software, hardware, platform, or storage providers, deliver their offerings over the Internet. Cloud providers typically charge monthly recurring fees based on your usage [2].

\section{DIFFERENT COMPUTING MODELS}

For understanding the concept of Cloud Computing it is very important to know the basic computing models which are related

to cloud computing. A Computing Model is a model which represents the architecture and process of computer system. Some of the important computing models which are related with cloud computing are given below.

\section{$>$ Desktop Computing \\ $>$ Client Server Computing \\ $>$ Cluster Computing \\ $>$ Grid Computing \\ $>$ Cloud Computing}

Let us discuss the above mentioned computing models:

\subsection{Desktop Computing Model}

It refers to single or individual Personal Computer which does not require any Network or Internet connection to work. A user can perform different types of operations in Desktop computer by installing different software's (such as MS Office, Auto Cad, Photoshop, Illustrators, 3D Studio Max, Dreamweaver, Net Beans, Visual Studio, CMS....etc).

It is applicable for both personal such as (working on Microsoft Office or Desktop publishing) and professional work such as (Engineers, Artists, Authors, Doctors, Programmers...etc).

Even a desktop computer is a personal computer that is designed to fit conveniently on top of a typical office desk. A desktop computer typically comes in several units that are connected together during installations such as a processor, the display monitor, and input devices - usually a keyboard and a mouse[3].

\subsection{Client Server Computing Model}

This type of computing model is mostly used for business purposes (such as Banks, Retails Stores, Marketing and Sales, Aviation Companies, Automobile Companies, Oil Industries,...etc). It is type of computing model in which all computers are connected with a Server where a Data Base is stored in the main server and application software will run on client machines.

A Client/Server computing model is a program relationship in which one program (the client) requests a service or resource from another program (the server). Although the client/server model can be used by programs within a single computer, it is a more important concept for networking. In this case, the client establishes a connection to the server over a local area network (LAN) or wide-area network (WAN), such as the Internet. Once 
the server has fulfilled the client's request, the connection is terminated [4].

\subsection{Cluster Computing Model}

As explained above in Client/Server computing model, let us see a situation or problem where we will see the solution called as Cluster Computing. Let us assume a business which is working on Client/Server model where many clients are running the application together and a database is stored on a heavy server, now let's imagine if the business grows and more client machines has to be added. If more client machines are added to the server then the server will suffer more loads. To balance the load sharing we either required to install a new server with the same configuration or a high configuration server called as Main Frame Server for providing services to the clients.

This kind of computing model is called as Cluster Computing. The most important thing to remember in Cluster Computing is that it works on Homogeneous Computing model where all clients and servers work together in a team as one computer, even the OS and Software's can also be same on both client and server.

\subsection{Grid Computing Model}

Grid computing is a Client/Server Computing special case. Now assume that a company has opened his different branches in different cities according to his business expansion where he requires more client and servers. If the business of the company keeps on expanding from city to city then the company will wish to have all the servers in one particular network that all different branches of the company can work as one single organization. These machines can be on different geographical locations and can be connected to a single network, which can be called as Grid. This is a special situation or case where servers are physically located in different geographical locations. The major difference between the Cluster Computing and Grid Computing that in Cluster Computing all the servers and machines are located in the same location where as in Grid Computing the servers and machines can be located in different geographical locations. The most important thing to remember in Grid Computing is that it works on Heterogeneous Computing model where all different servers (such as Data base Server, Mail Server, File Server...etc for different services) and even different OS work together as one system which is referred as Grid Computing model.

\subsection{Cloud Computing Model}

Cloud computing is the combination of Cluster and Grid Computing (as explain above). Cloud Computing is just a computing model as other models which are discussed above but not a new technology.

In cloud computing, the word cloud is used as a metaphor for "the Internet," so the phrase cloud computing means "a type of Internet-based computing," where different services (such as servers, storage and applications) are delivered to an organization's computers and devices through the Internet.

\section{EVOLUTION OF CLOUD COMPUTING}

Before understanding the evolution of Cloud Computing we need to know the evolution of Internet as how Internet came into existence and how it had grown to this level as we can get the clear idea how cloud was evolved.

Evolution of Internet - In US universities computer servers were used earlier. Some universities were situated in East coast and some universities where in West coast. A new project was started called as ARPANET and the main objective of this project was to connect all those servers in one network and later connect that network with military network so that the Researchers and Professors working in the universities can help the military.

ARPANET was started in 1969 and in this E-mail service was introduced in 1972 followed by WWW which was made available for common public in 1991 which uses Web servers. Now let us see the difference between E-mail and Web server, E-mail is a simple one to one or one to many type of communication system where as a website acts as a notice board in which papers are posted and who ever wish to read those papers comes and read it. Website is stored in web server which is been connected to Internet and hence can be accessed via any means of client machines such as Mobile, PC, PAD, Laptop, Tab etc.

When internet became available for common people then many companies started using this as commercial business and every company wishes for opening their own websites and attract the customers. Hence many companies started to connect their servers in this network and started hosting their websites in the internet to attract the customers. A new era was started in Internet called as Dot Com bubble in 2000 where many companies started to make their own websites and even serve their customers which were spread all over the world continents. In this manner the Cloud Computing came into existence with many companies such as GoDaddy, Dream Host, Blue Host, etc started providing the services all over the world.

Ravi Namboori (Nov 14, 2014) described that Cloud computing has its roots as far back in 1950s when mainframe computers came into existence. At that time, several users accessed the central computer via dummy terminals.

In 1970s, IBM came out with an operating system (OS) named VM. This allowed for simultaneous operation of more than one OS. Guest Operating Systems could be run on every VM, with their own memory and other infrastructure, making it possible to share these resources. This caused the concept of virtualization in computing to gain popularity. And then in 1990s witnessed telecom operators begin offering virtualized private network connections, whose quality of service was as good as those of point-to-point (dedicated) services at a lesser cost. This paved way for telecom companies' to offer many users shared access to a single physical infrastructure.

Clouds are of four types- public, private, community, and hybrid. Through public cloud, a provider can offer services, including storage and application, to anybody via the Internet. They can be provided freely or charged on a pay-per-usage method. Public cloud services are easier to install and less expensive, as costs for application, hardware and bandwidth are borne by the provider. They are scalable, and the users avail only those services that they use. Where as a private cloud is referred to as also internal cloud or corporate cloud, and it called so as it offers a proprietary computing architecture through which hosted services can be provided to a restricted number of users protected by a firewall. As far as the community cloud is concerned, it is resources shared by more than one organization whose cloud needs are similar. A combination of two or more clouds is a hybrid cloud. Cloud computing is now being adopted by mobile phone users too, although there are limitations, such as storage capacity, life of battery and restricted processing power.

Some of the most popular cloud applications globally are Amazon Web Services (AWS), Google Compute Engine, Rackspace, Salesforce.com, IBM Cloud Managed Services, 
among others. Cloud services have made it possible for small and medium businesses (SMBs) to be on par with large companies [5].

\section{BENEFITS OF CLOUD COMPUTING}

Cloud Computing means hiring or renting Servers by means of Internet for Public Clouds. Some of the benefits of Cloud Computing are listed below:

\subsection{Cost}

If any company runs its own server setup where all client machines are connected with it, then for handling such activities the company requires more cost for setup and maintenance such as hardware issues, server issues, hiring a professional, purchasing the licensed software's, and many more, which are termed as Recurring cost where the company needs to bear on it to maintain the IT infrastructure and run the business. But in Cloud computing if such kind of company takes services on Cloud then the client machines can take services from Internet where software can also run and all maintenance issues can easily be handled by means of Cloud Companies, which reduced all the recurring costs. The company can take services from Cloud on rented basics according to their needs.

\subsection{Device and Location Independent}

If our server is located on cloud that means on Internet then we can access it from any location with any device. Hence these days the latest trend is going on as companies are information their employees to work from home by means of either cloud network or Virtual Private network. This is the major advantage of Cloud Computing where software's can be stored online on internet and the employees can perform their work from their home premises.

\subsection{Virtualization and Multi-Tenancy}

The cloud companies actually provide Virtual Private Servers on rent rather than Physical servers. The technology which is used for making the Virtual Servers is called as Hypervisors. The famous and most widely used Hypervisors are VMware, Citrix, and Windows 2008.

The concept of Multi-Tenancy can better be explained by giving the example of an apartment or condominium where multiple numbers of tenants live together in the same block or building. In the same manner in the Storage Area Network of Cloud numerous amount of Clients data is been stored where Servers are also host on Clouds.

\subsection{Reliability and Security}

Cloud is nothing but a Grid of Data centers. Just assume that if one Data Center in Cloud is situated in East and the other on West, when both are performing their operations via Cloud then One becomes the Primary data centre and other becomes the Back Up Data centre, in case of any natural disaster the data is been saved by means of Back Up Data Center where the application can run easily. Hence we can say that the Cloud servers are more reliable.

When a common business organization can take the maximum measures to secure its own data, then just imagine that how Cloud can take measurements to secure its own data. It's a myth among many people that the data in the Cloud is not secure, but now days the cloud has taken many advanced security protection techniques by which the companies are satisfied and are happily ready to take services from cloud.

\subsection{Scalability/Elasticity and Maintenance}

Few types of businesses required the services of cloud servers temporarily or seasonally, in such cases the company can reduce or increase the amount of servers according to their requirements or needs by just adding the servers on a click by entering in their cloud account. Hence it becomes so simple for a business to work according to their requirements where all the maintenance work can be done easily by cloud services.

\subsection{Software Delivery}

This is one of the major advantages of Cloud Computing. In cloud if you want to access any software you no need to install that software on your system, you just need to open the browser and type the URL and the software will be ready to run in your browser. Whatever tasks or work you are doing on that browser that will be saved easily in cloud. For business use also the ERP software are available on cloud for access, which means that your system doesn't have that software but cloud is delivering that software by means of internet via browser which is called as Software delivery.

\section{CHARACTERISTICS OF CLOUD COMP...}

\subsection{Agility}

In Cloud the agility is referred as Fastness. Since Cloud works in a Distributed Computing environment which means it does not works on a Point to Point connection basis but rather works on One to Many connections, hence Cloud functions its operations faster.

Rus Healy (October 02, 2016) describes that one of the greatest benefits of the cloud lies in its agility. For organizations ready to migrate one or more applications, the journey to the cloud can be just as flexible and customizable.

Small businesses, large enterprises, healthcare facilities, government agencies, and education institutions must all take into account their own varying degrees of security and compliance regulations, bandwidth usage, software compatibility, risk tolerance, and business drivers, to determine which cloud solution or solutions will drive the most value [6].

\subsection{Reliability}

The question can be raised as how Cloud is reliable? Since we knew that Cloud works on Distributed Computing Environment, so the availability of servers on cloud are always possible via internet.

If for any untoward reasons any dedicated server stops working then we do not need to worry about the data present on that server as there will be always a backup server available to handle such kind of situation. Hence in this way Cloud are more reliable.

\subsection{Multi-casting}

With the help of cloud multiple users and clients can work more efficiently because cloud consists of very strong infrastructure, hence cloud can deal with multiple users and multiple tasks at the same time.

In a cloud Multicasting takes place by providing communication between a single sender and multiple receivers on a network.

\subsection{Maintenance}

Maintenance of Cloud Computing application is easier since they do not need to be installed on each user's computer. Suppose we have to install an operating system on each (Client/user) participants of a cloud, then we do not need to 
install it on each and every computer individually. We can install it at single time and at once, hence making it simple to maintain and also reduce the cost.

Mike Klein (September 13, 2010) describes as maintenance is driven by two factors, less hardware and outsourced, shared IT staff. Because cloud computing uses very few physical resources, there is less hardware to power and maintain. With an outsourced cloud, you don't need to keep server, storage, network, and virtualization experts on staff as full time. You get economy of scale of those expert resources through your cloud provider [7].

\subsection{Low Cost}

By using cloud computing the cost will be reduces because to take the services of Cloud Computing, the IT companies do not need to setup its own infrastructures. Example it a company needs a services of E-mail servers then they do not need to set its own infrastructures, they can just hire the services of Google by paying the amount prescribed.

\section{CLOUD COMPUTING SERVICES}

Cloud Computing is a business. Let us see some services available in cloud computing. We have discussed that cloud computing is the combination of both cluster and grid computing. Some reputed companies such as Toyota, City Bank and Walmart, etc have their own private cloud which functions or provide access within their premises.

Even these days in internet there are some companies which have their own clouds such as Google, Microsoft, HP, IBM, Facebook, Salesforce, which provides technical assistance and support to the other companies on rent basis. Now before understanding the services provided by cloud computing, let us discuss the basic requirements of Servers, or what are all the things which are available in servers?

The first requirement is Hardware and Networking which can be termed as Infrastructure. The second requirement is Operating System which can be termed as Platform, where we need to install the Operating System in the Hardware as without Operating System no machine can perform its tasks. Now finally the third requirement, on that Operating System we are going to install the Application according to our needs, which we will say as Software. If it is a business application then it may be any ERP or if it is a personal application then it can be personal computing software whatever we uses.

In the same manner if we take any services on rent by Cloud then we are going to have three different options or choices such as given below:

\subsection{Infrastructure as a Service}

In this you may opt for any hardware or networking services that means Infrastructure as explained above in which you install any Operating System of your choice and deploy any software whatever you wish to work on. This kind of services is called as IaaS.

Infrastructure as a service (IaaS) is a service model that delivers computer infrastructure on an outsourced basis to support enterprise operations. Typically, IaaS provides hardware, storage, servers and data center space or network components; it may also include software. Infrastructure as a service (IaaS) is also known as hardware as a service (HaaS).

\subsection{Platform as a Service}

Some cloud companies already have existed infrastructure and their own platform such as Windows based, Linux based or some may have created their own platform. Here in such kind of services Infrastructure and Platform will be their own, you just need to pay the rent or charges and also you can create or deploy your own application and run according to your needs.

Hence this kind of services is called a PaaS, which are the combination of Infrastructure and Platform.

Platform as a service (PaS) is a concept that describes a computing platform that is rented or delivered as an integrated solution, solution stack or service through an Internet connection. The solution stack may be a set of components or software subsystems used to develop a fully functional product or service, such as a web application that uses an OS, web server, database and programming language. More generically, the solution stack may deliver an OS, middleware, database or application.

In Platform as a service, cloud computing provides computing platform and system software as a service. Cloud users create an application by controlling software deployment and configuration settings from the providers. When we look at security point of view, host based, and network based intrusions are challenging factors of PaS providers. The major PaaS level security threats are in Data Location and Privileged access [8].

\subsection{Software as a Service}

In this service collection of software's are pre installed, and you can use your own software according to your need and have to pay the rent according to the usage. Hence SaaS is the combination of IaaS and PaaS. Software as a service ( $\mathrm{SaaS}$ ) is a model for the distribution of software where customers access software over the Internet. In SaaS, a service provider hosts the application at its data center and a customer accesses it via a standard web browser.

From the security aspects in SaaS, the client has to depend on the provider for proper security measures. The provider must do the work to keep multiple users' from seeing each other's data. So it becomes difficult for the user to ensure that right security measures are in place and it is also complicated to get assurance that the application will be available when needed to avoid the risks of maintaining high availability problems by having multiple copies of the data.

\section{CONCLUSION}

Hence from this paper the conclusion can be made that Cloud Computing is a computing model similar to different types of computing models which have been discussed in this paper, and it is not a new technology. A cloud computing is just a combination of Cluster and Grid Computing models.

\section{REFERENCES}

[1] Eric Griffith (May, 03, 2016). What is Cloud Computing? Retrieved from http://in.pcmag.com/networkingcommunications-software/38970/feature/what-is-cloudcomputing [Accessed 02 January, 2017]

[2] Gajender Pal, Kuldeep Kumar Barala, Mahish Kumar (September-2014), A Review Paper on Cloud Computing. IJRASET. Vol.2 Issue 9. pp 401-403.

[3] Margaret Rouse (October 2008), Retrieved from. http://searchenterprisedesktop.techtarget.com/definition/de sktop-computer [Accessed on 26th December 2017]

[4] Margaret Rouse (October 2008), Retrieved from. http://searchnetworking.techtarget.com/definition/clientserver [Accessed on 26th December 2017] 
[5] Ravi Namboori (November 14, 2014), Retrieved from Cloud Zone. https://dzone.com/articles/cloud-computing-1 [Accessed 13th January 2018]

[6] Rus Healy (October 02, 2016). The 5 essential Characteristics of Cloud Computing. Retrieved from https://www.annese.com/characteristics-of-cloudcomputing [Accessed $12^{\text {th }}$ January 2018]

[7] Mike Klein (September 13, 2010). The Six Benefits of Cloud Computing. Retrieved from http://resource.onlinetech.com/the-six-benefits-of-cloudcomputing/ [Accessed on $14^{\text {th }}$ January 2018]

[8] Mohammed Khalid Kaleem, Manaullah Abid Hussain, Suneel Dubey, (November-2015), An Analysis upon various security problem in Cloud based E-Learning environment. International Journal of Information Technology and Management. Vol 1X, Issue No XIV.

[9] Abdul Bari (20 th April 2014). Cloud Computing - Hindi \#1. (Video File) Retrieved from https://youtu.be/OcKm6vLJcA0

[10] Abdul Bari (22 ${ }^{\text {nd }}$ April 2014) Cloud Computing - Hindi \#2. (Video File) Retrieved from https://youtu.be/4SZPm26nUEA

[11] Abdul Bari (29 ${ }^{\text {th }}$ April 2014) Cloud Computing ServicesHindi -\#3.(Video File) Retrieved from https://youtu.be/Tu_AmhKOMH4

[12] Abdul Bari (30 ${ }^{\text {th }}$ April 2014) Cloud Computing Benefits Hindi - \#4. (Video File) Retrieved from https://youtu.be/v0Rp6hYf7g

[13] Arshadeep Bagha and Vijay Madisetti (December 2013). Cloud Computing-A Hands on Approach.

[14] .Kasi Viswanath, S.Kusuma and Saroj Kumar Gupta (2012). - Cloud Computing Issues and Benefits. Global Journal of Computer Science and Technology Cloud \& Distributed., Vol. 12 Issue 10 Version 1.0 pp.15-19, July 2012.
[15] Evolution of Cloud Computing, Retrieved from .http://www.exelanz.com/blogs/evolution-of-cloudcomputing/ [Accessed on $12^{\text {th }}$ January 2018]

[16] Gharehchopogh FS, Hashemi S. (2012). Security challenges in Cloud computing with more emphasis on trust and privacy. International Journal of Scientific and Technology Research; 1(6): pp. 49-54.

[17] Hurwitz, J., Bloor, R., Kaufman, M., Halper, F.: Cloud Computing for Dummies. Wiley (2010) Issues, "International Journal of Computer, Information, Systems and Control Engineering, vol. 7, no. 9.

[18] M. Creeger, "CTO Roundtable: Cloud Computing,", Aug. 2009.

[19] Piplode R, Singh UK. An overview and study of security issues and challenges in cloud computing. Int $\mathrm{J}$ Adv Res Computer Science Software Eng. 2012 Sep; 2(9).

[20] Ray J Rafael's (April 2015) Cloud Computing-From Beginning to End. Published by Createspace Independent Publishing Platform.

[21] Santosh Kumar, R H Goudar (December 2012), Cloud Computing-Research Issues, Challenges, Architecture, Platform and Applications: A survey. International Journal Future Computer and Communication. Vol 1, Issue No 4. Pp 356-360.

[22] Takabi H, Joshi JBD, Ahn G. (2010). Security and privacy challenges in cloud computing environments. IEEE Security Privacy Magazine. IEEE Computer Society. 2010; 8: pp. 24-31.

[23] Vangie Beal, Cloud Computing. Retrieved from www.webopedia.com/TERM/C/cloud_computing.html [Accessed on 28th December 2017] 